JESSICA JIE YING ONG AND EMILY BRAIN

\title{
Malaria in New Zealand - Using Art Science to spread a message
}

\section{INTRODUCTION - JESSICA ONG}

Avian malaria parasites cause morbidity and mortality in birds. Although malaria is not a threat to humans in New Zealand, it is an increasing threat to endangered birds. Although we perceive New Zealand to be malaria-free, this is not the case: avian malaria-transmitting mosquito vectors such as Culex and Aedes thrive in New Zealand. As of today there are at least four avian malarial species identified in 35 endemic New Zealand birds. ${ }^{1-3}$

In a collaboration with Penguin Rescue (Moeraki, New Zealand), post-doctorate research fellows in the Russell Lab of the Microbiology Department are in the process of understanding avian malaria species and their development in Megadyptes antipodes (yelloweyed penguin; Maori name: hōiho). Blood smears are regularly examined by trained microscopists to identify parasites in penguin blood (Figure 1). Even with this most reliable approach, slide examination is labour intensive and low-level parasite infections go unnoticed.

We took the opportunity to combine art and science to create an exhibit for raising public awareness about avian malaria in the endangered hōiho (Figures 2 and 3). The debilitating "mal'aria" (Italian for "bad air"), was derived from the foul smelling Pontine marshes (which degraded after logging), and was a suspected source of illness over large areas of Rome. ${ }^{4}$ As such, the Romans drained

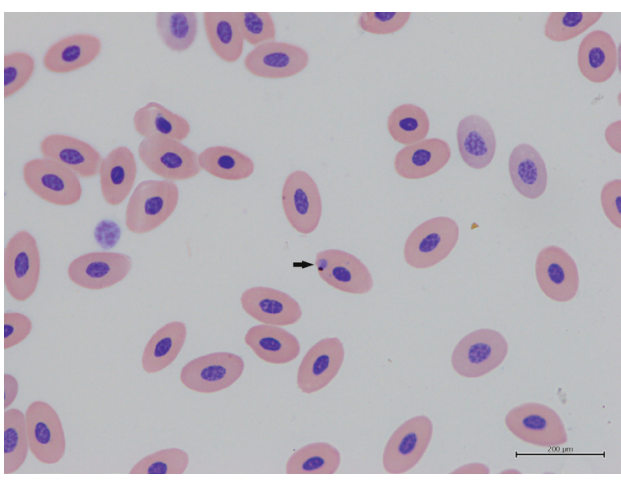

Figure 1. Giemsa stain of a thin blood film from a yellow-eyed penguin (hōiho) Plasmodium spp (solid arrow) residing in a mature red blood cell (rbc). Avian rbc contain nuclei. Like the nucleus, the parasite's cytoplasm, rich in genetic material, is also stained blue. The hemozoin, by product of malaria parasites, is stained black. Scale bar $=200 \mu \mathrm{m}$. 
stagnated swamps (a breeding ground for malaria-transmitting mosquitos) to combat "mal'aria". Stagnant water removal continues to be part of the three-pronged approach in modern human malaria elimination programmes (these include intermittent preventive treatment, insecticidetreated nets, and prompt and effective case management). Yet malaria is far from eradicated. ${ }^{5}$ This article reviews the human and avian malaria life cycle, and discusses challenges around controlling avian malaria disease in endemic endangered birds.

\section{BRIEF HISTORY OF MALARIA}

The symptoms of malaria disease include fever, anemia, weight loss, and enlargement of the spleen. In human hosts, fever is timed to the release of blood stage merozoites, which invade new red blood cells (erythrocytes), and recurs every 48 or $72 \mathrm{~h}$, depending on the malaria species infected. Each infected erythrocyte will undergo schizogony (asexual reproduction) which matures 18-24 more merozoites. When released, the merozoites go on to infect more erythrocytes. The infected blood cells flow through the body and can sequester in blood capillaries and organs such as the spleen and brain. ${ }^{6}$ It is during this period that patients become symptomatic.

The earliest evidence of malaria (Plasmodium dominicana) was found in the body cavity of a Culex mosquito in Dominican amber. ${ }^{7}$ This avian malaria species is thought to establish in hosts of the order Galliformes (heavy body ground feeding birds). Common in all malaria species, the parasite requires a vertebrate and vector (mosquito) host for continuous transmission. Discovery of avian malaria (Plasmodium relictum) transmission through mosquitos was discovered by Ross in 1898, studying sparrows and Culex mosquitos. ${ }^{8}$

\section{AVIAN MALARIA}

Like human malaria, avian malaria also weakens its host's immunity. The key difference between human and avian malaria is the host cells which the erythrocytic merozoites invade. Avian merozoites invade reticulo-endothelial cells (macrophages found in specialised organs such as lungs, bone marrow, spleen, and lymph node). ${ }^{9}$ This poses a significant challenge to treating infected birds with blood-targeting drugs because these cannot reach parasites hidden in organs.

\section{Brief overview of avian malaria studies}

Avian malaria can be transmitted by Culex, Mansonia, Culiseta and Aedeomyia spp (and in laboratory settings, Aedes, Anopheles and Armigeres spp). ${ }^{10,11}$ While our investigations identify vectors for avian malaria transmission, utmost concern is also for the impact of climate change on the mosquitos that transmit malaria. Under controlled laboratory conditions, increased temperatures $\left(30-35{ }^{\circ} \mathrm{C}\right)$ accelerate egg emergence and adult development in Culex spp. ${ }^{12,13}$ Interestingly, accelerated development also means that mosquitos will reach mortality quicker upon adulthood. However, it is unknown if Plasmodium sporogony would similarly increase in Culex spp at high temperatures.

In the wild, a higher proportion of malaria-infected birds is located at lower altitudes. ${ }^{14-18}$ While it is generally assumed that lower altitudes are warmer than higher altitudes, these studies fail to indicate sampling bias due to sick and weak birds not caught in mist nets. Hence, there might be no correlation between altitude and avian malaria, as was suggested by a study along an elevational gradient in Nelson Lakes National Park. ${ }^{18}$ 
Loss of native birds due to malaria disease outbreaks have been recorded worldwide, with the largest loss recorded in Hawaii, where more than half of Hawaiian honeycreepers have gone extinct due to high transmission of avian malaria and a pox virus. The loss of honeycreepers has led to implementation of various prevention measures to limit vector-borne diseases by minimising the conditions for mosquitos to lay eggs (i.e. stagnant water). The identification of such water sources and their mitigation actions are listed in Table 1. Although the topgraphy of New Zealand is different to Hawaii, some of these measures are still viable options to control vector-borne disease transmission. ${ }^{19}$

Table 1. Risk assessment paradigm for native bird extinction risks caused by vector-borne diseases

\begin{tabular}{|c|c|c|}
\hline Step & Aim & Source / Action \\
\hline \multirow{3}{*}{$\begin{array}{l}\text { 1. Elimination of } \\
\text { standing water } \\
\text { resources }\end{array}$} & Man-made & $\begin{array}{l}\text { Manage water source on agriculture and ranch } \\
\text { lands }\end{array}$ \\
\hline & & $\begin{array}{l}\text { Formation of unified conservation in watershed } \\
\text { partnerships (mid- and high-elevation) }\end{array}$ \\
\hline & Natural & $\begin{array}{l}\text { Ground holes dug by hooved/ground mammals } \\
\text { Strategise with fencing to manage movement }\end{array}$ \\
\hline \multirow{2}{*}{$\begin{array}{l}\text { 2. Ongoing studies } \\
\text { of mosquito } \\
\text { population }\end{array}$} & Surveillance & $\begin{array}{l}\text { Limit mosquito reproduction with Wolbachia } \\
\text { bacteria-mosquitos }\end{array}$ \\
\hline & & $\begin{array}{l}\text { Tree holes larvicidal treatment using Bacillus } \\
\text { thuringiensis var. israelensis (BTI) for } \\
\text { longtitudinal entomology surveillance }\end{array}$ \\
\hline \multirow[t]{2}{*}{ 3. Host Immunity } & Prevent loss of rare alleals & Protect and manage bird populations \\
\hline & Increase genetic diversity & Captive propagation and translocation \\
\hline
\end{tabular}

Figure 2. Table 1 - Risk assessment paradigm for native bird extinction in Hawaii. ${ }^{20}$

\section{MALARIA PREVENTION}

The current malaria prevention programme heavily emphasises mosquito vector reduction or control, either by removing standing water or applying larvicide to water pools. ${ }^{21,22}$ In this sense, water has been the main focus to reduce malaria prevalence as it is assumed that the removal of water for mosquito egg laying will halt disease transmission. Although the mosquito egg laying surface (i.e. water) has been, from the start, the essence of eradicating malaria, mathematical models have also highlighted the need for preventing sporadic infections from becoming expanding rates of infection. ${ }^{23}$ Measurable variables such as number of infected mosquitos in a finite mosquito population (where mosquito abundance relates to frequency of mosquito feeding) indicate the likelihood of getting an infection. The conditions that influence the rate of transmission between readily infected hosts and vectors should also be incorporated. This includes, but is not limited to, biological factors such as host susceptibility, rate of recovery, disease phenotype (relapsing vs nonrelapsing), and climatic factors such as temperature, rainfall, humidity, wind speed and direction, and the distance between hosts-vectors. ${ }^{24,25}$ 
With regards to endangered birds, which are already struggling with reproduction, the downward reproductive trend continues to limit their gene pool and their immunity levels to combat malaria disease. Furthermore, although use of insecticides and antimalarial drugs would suppress avian malaria transmission temporarily, it simultaneously encourages adaptation of drug-resistant superbugs in mosquitos and malaria parasites respectively. Hence, New Zealand will require a multiple-prong and innovative approach to manage vector disease transmission in order to conserve its vulnerable native bird species.

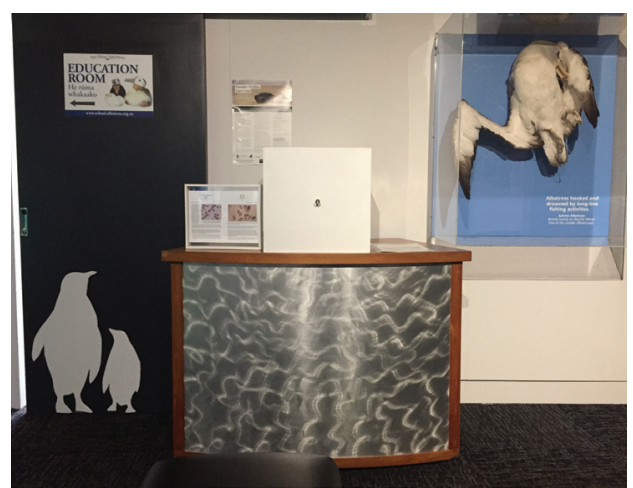

Figure 3. Avian malaria exhibit display at the Royal Albatross Centre public gallery.

\section{HOIHO UNDER THE MICROSCOPE - EMILY BRAIN}

Mosquitos are the vectors for a variety of diseases and parasites, and pose a threat to both humans and animal species. While malaria is not a present threat to humans in New Zealand, avian malaria is infecting native species of birds and can affect future population growth.

To monitor human diseases spread by mosquitos, Australian scientists use traps to collect samples of adult populations and water samples to look for larvae. In New Zealand additional information is gathered by testing blood samples from infected populations and performing manual counts of the avian malaria parasites in a blood smear. This takes place under a microscope and is time consuming and labour intensive.

Not a lot is known about how we can control mosquito populations and the illnesses they carry in New Zealand but countries like Australia, with a high risk of human infection, use public awareness as a tool to help limit the spread. In Australia, advice on managing mosquito-spread illnesses is split into two common categories: preventing mosquito bites, and preventing mosquito breeding. There is little we can do to prevent bites in wild bird populations; preventing mosquito breeding is a

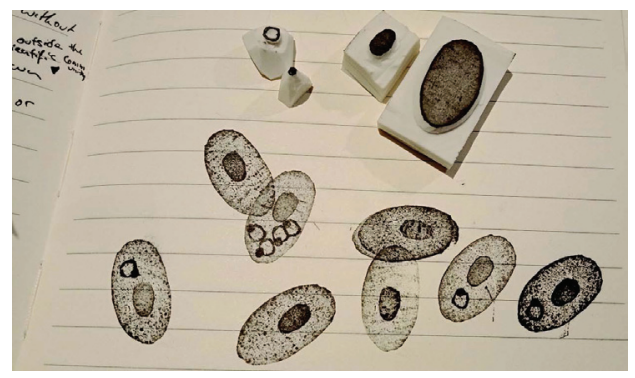

Figure 4. Hoiho under the microscope work in progress, interpretation of Giemsa stain of a thin blood film from a yellow-eyed penguin. Photograph: Emily Brain.

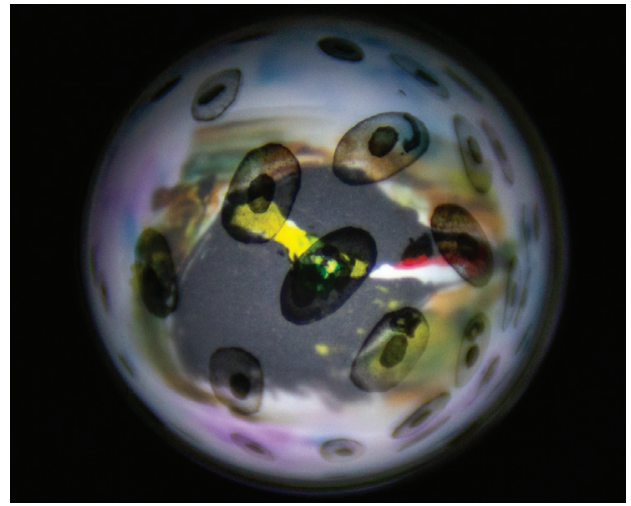

Figure 5. Emily Brain and Jessica Ong, Peering through the eyepiece shows a layer of parasitized red blood cells illuminated over a drawing of a hōiho. Photograph: Pam McKinlay. 
more achievable goal. With community action in mind, the "Fight the Bite" campaign in Western Australia includes advice such as preventing stagnant water from gathering in containers and encourages families to check their home for, and cover or remove, containers which might be breeding places for mosquito larvae.

This approach can be utilised in New Zealand as mosquito populations grow in the rising temperatures of climate change. Digital and print media can be a resource for educating the public, and people can better understand and take action to prevent mosquito breeding within their household, or in industrial or farming areas.

\section{ACKNOWLEDGMENTS - JESSICA ONG}

This work is supported by University of Otago Department of Microbiology and Immunology, Penguin Rescue, and Otago Polytechnic. I thank my supervisor Bruce Russell, post doctoral research fellows, our collaborators at Penguin Rescue, and Otago Polytechnic artists Emily Brain and Pam McKinlay, who contributed valuable information and making of exhibits towards avian malaria in New Zealand. Thanks also to Bruce Mahalski for sharing a biography on Ronald Ross, and lastly, Sally Carson, Hoani Langsbury and their colleagues for displaying and looking after the exhibit indefinitely at the Royal Albatross Centre, Dunedin, New Zealand.

Jessica Jie Ying Ong ( (- ORCID No 0000-0002-5096-8728) is a PhD student at the Department of Microbiology and Immunology, University of Otago. Her research investigates erythrocytic human relapsing malaria, Plasmodium vivax. She is a co-author in three publications with high impact journals (Blood, Biomaterials, and Nature Communications (shared first author)).

Emily Brain is an Australian-born Jewellery and Metalsmithing graduate from the Dunedin School of Art. 
1. L Howe, et al., "Malaria parasites (Plasmodium spp.) infecting introduced, native and endemic New Zealand birds," Parasitology Research 110, no. 2 (2012): 913-23.

2. E R Schoener, et al., "Presence and diversity of mixed avian Plasmodium spp. infections in introduced birds whose distribution overlapped with threatened New Zealand endemic birds," New Zealand Veterinary Journal (2019): 1-6.

3. E R Schoener, et al., "Avian malaria in New Zealand," New Zealand Veterinary Journal 62, no. 4 (2014): 189-98.

4. P Carcaterra, "Rome and malaria," Medicina Secoli 10, no. 3 (1998): 557-77.

5. World Health Organization, World malaria report (2019).

6. W Pongtavornpinyo, et al., "Probability of emergence of antimalarial resistance in different stages of the parasite life cycle," Evolutionaly Applications 2, no. 1 (2009): 52-61.

7. G Poinar, Jr., "Plasmodium dominicana n. sp. (Plasmodiidae: Haemospororida) from Tertiary Dominican amber," Systematic Parasitology 61, no. 1 (2005): 47-52.

8. A Dutta, "Where Ronald Ross (1857-1932) worked: the discovery of malarial transmission and the plasmodium life cycle," Journal Medical Biography 17, no. 2 (2009): 120-2.

9. A Rivero, and S Gandon, "Evolutionary Ecology of Avian Malaria: Past to Present," Trends in Parasitology 34, no. 8 (2018): 712-726.

10. G Valkiunas, et al., "A new Haemoproteus species (Haemosporida: Haemoproteidae) from the endemic Galapagos dove Zenaida galapagoensis, with remarks on the parasite distribution, vectors, and molecular diagnostics," Journal of Parasitology 96, no 4 (2010): 783-92.

11. W J Niles, M A Fernando, and A S Dissanaike, "Mansonia crassipes as the natural vector of filarioids, Plasmodium gallinaceum and other plasmodia of fowls in Ceylon," Nature 205 (1965): 411-2.

12. K C Ng, et al., "Increased adult Aedes aegypti and Culex quinquefasciatus (Diptera: Culicidae) abundance in a dengue transmission hotspot, compared to a coldspot, within Kaohsiung City, Taiwan," Insects 9, no. 3 (2018): 98.

13. A T Ciota, et al., "The effect of temperature on life history traits of Culex mosquitoes," Journal of Medical Entomology 51, no. 1 (2014): 55-62.

14. M R Alley, et al., "An outbreak of avian malaria in captive yellowheads/mohua (Mohoua ochrocephala)," New Zealand Veterinary Journal 56 , no. 5 (2008): 247-51.
15. D Gudex-Cross, et al., "Mosquito communities and avian malaria prevalence in silvereyes (Zosterops lateralis) within forest edge and interior habitats in a New Zealand regional park," Ecohealth 12, no. 3 (2015): 432-40.

16. D C Sijbranda, et al., "Cases of mortality in little penguins (Eudyptula minor) in New Zealand associated with avian malaria," New Zealand Veterinary Journal 65, no. 6 (2017): 332-337.

17. D A LaPointe, M L Goff, and C T Atkinson, "Thermal constraints to the sporogonic development and altitudinal distribution of avian malaria Plasmodium relictum in Hawai'i," Journal of Parasitology 96, no. 2 (2010): 318-24.

18. C N Niebuhr, R. Poulin, and D M Tompkins, "Is avian malaria playing a role in native bird declines in New Zealand? Testing hypotheses along an elevational gradient," PLoS One 11, no. 11 (2016): e0165918.

19. C T Atkinson, and D A LaPointe, "Introduced avian diseases, climate change, and the future of Hawaiian honeycreepers," Journal of Avian Medicine and Surgery 23, no. 1 (2009): 53-63.

20. W Liao, et al., "Mitigating future avian malaria threats to Hawaiian forest birds from climate change," PLoS One 12, no. 1 (2017): e0168880.

21. Y Geissbuhler, et al., "Microbial larvicide application by a large-scale, community-based program reduces malaria infection prevalence in urban Dar es Salaam, Tanzania," PLoS One 4, no. 3 (2009): e5107.

22. L S Tusting, et al., "Mosquito larval source management for controlling malaria," Cochrane Database Systematic Review 8 (2013): CD008923.

23. E Nye and M Gibson, Ronald Ross: Malariologist and polymath (London: Palgrave McMillan, 1997).

24. J Nedelman, "Estimation for a model of multiple malaria infections," Biometrics 41, no. 2 (1985): 447-53.

25. P Goswami, et al., "A model of malaria epidemiology involving weather, exposure and transmission applied to north East India," PLoS One 7, no. 11 (2012): e49713. 